\title{
Hitting the Mark- Facilitating Research Administration to Support the Institutional Strategic Plan
}

\section{Ian Czarnezki, MBA, Director of Operations, Office of the Vice President for Research, Kansas State University}

$\mathrm{T}$

This paper explores the challenges of facilitating research administration and monitoring progress towards the institutional strategic plan. Kansas State University has a bold vision of being recognized as one the nation's Top 50 Public Research Universities by 2025 (K-State 2025). ${ }^{1}$ This bold vision presents a significant challenge for research leadership, how to effectively monitor progress and facilitate growth.

The goal

K-State 2025 identifies two primary sources for assessing our progress towards the research related goals; Na- tional Science Foundation Higher Education Research and Development Survey and Arizona State University Center for Measuring University Performance'.

Figure 1. Kansas State University research expenditures between FY1990 - 2009

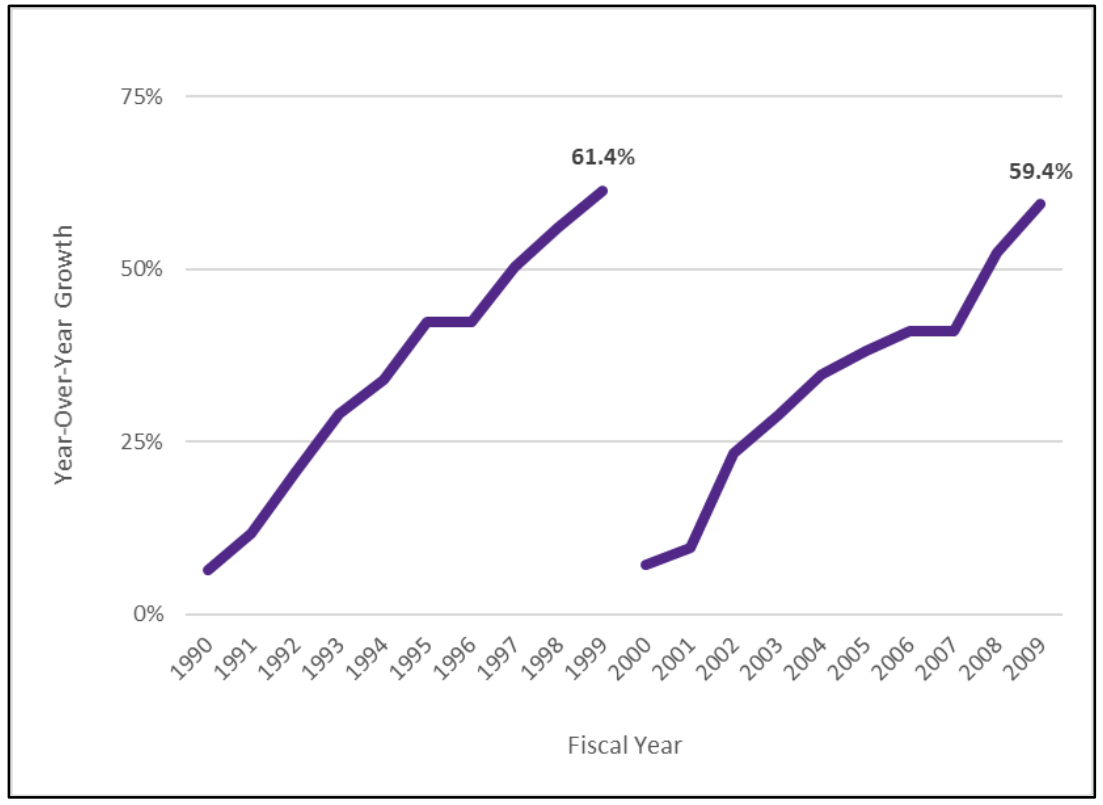

National Science Foundation 1992 Academic S\&E R\&D Expenditures, Table B-32 2 National Science Foundation 1997 Academic R\&D Expenditure, Table B-32 3 National Science Foundation 2015 Higher Education Research \& Development, Table 164 


\section{Our progress}

Due to the scope of K-State 2025 we need the ability to understand how each research award impacts our progress. One of the primary challenges to achieving this level of monitoring is integrating the various systems supporting research administration. Kansas State University leverages multiple systems to support our research administration efforts; human resource information system, financial information system, and research administration system. Each of these systems plays an integral role in the overall administration of the research enterprise, unfortunately each system has unique constraints. For example, the human resource information system is bound by the official reporting structure, which presents issues for monitoring multidisciplinary and cluster hire research activities. The financial information system captures transactions associated with research, but is blind to the full research award. In order to accurately assess our progress towards our institutional goals we need to harvest information from each of these disparate systems. Kansas State University has undertaken a reporting initiative to provide a cohesive and timely view of our research activity. Figures 2 and 3 provide an overview of several of the outputs from this initiative.

K-State Consolidated Award Tracking System (K-CATS) is our branded research administration business intelligence solution. This solution allows both research leadership and a broad community of stakeholders' insight into our research activities. Figure 2 is screenshot of K-CATS Sponsored Research Award Activity overview, which provides research leadership with near real-time access to award activity and gives greater insight with historical context. In addition the Kansas State Research Awards Dashboards provide a broad audience, including both internal and external stakeholders, with an overview of the current research activities. The dashboards are accessible via the Kansas State University website at http://www.k-state.edu/research/our-research/reports/dash-

boards.html 


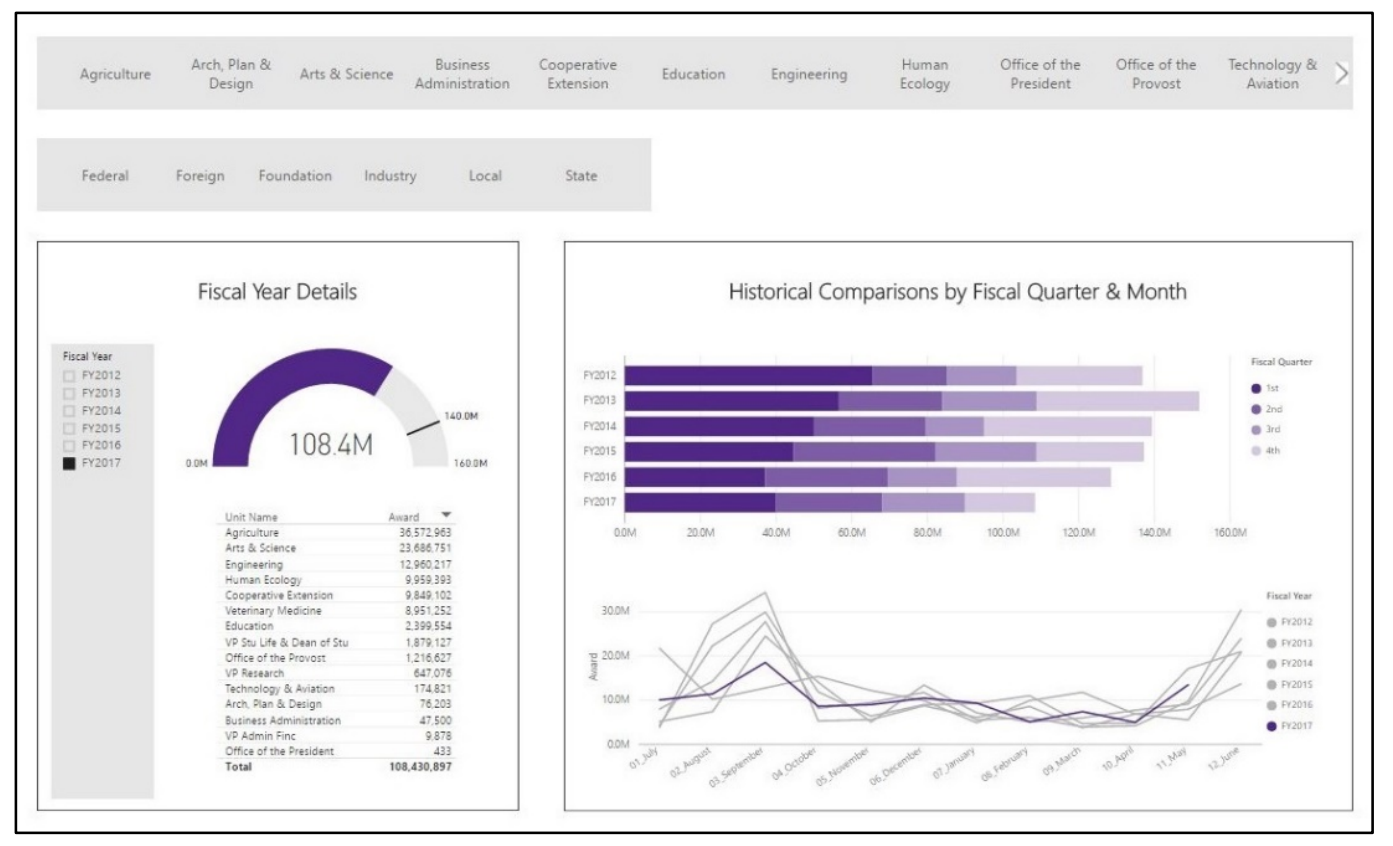

Figure 2. K-CATS Sponsored Research Award Activity

Currently underway, the HERD Project is a collaborative effort between Kansas State University and Microsoft. The objective of this collaboration is the development of a reporting solution for the National Science Foundation Higher Education Research Development Survey. The reporting solution will consolidate the survey's data files into a single interactive business intelligence solution thus allowing for great insight into our research activities compared to other institutions. Figure 3 is a draft visualization from the reporting solution which provides an interactive overview of Kansas State University research expenditure profile. Users can interact with the visualization by changing the fiscal year, drill through the disciplines hierarchy (engineering, science, life sciences, etc.) and filter by funding source. It is critical we empower our leadership with as much insight from National Science Foundation HERD Survey as possible, as K-State 2025 identifies it as a primary source of assessing our research activities. Once the project is completed, it is anticipated the reporting solution will be accessible via the Kansas State University website and will be shared with other higher education institutions upon request. 


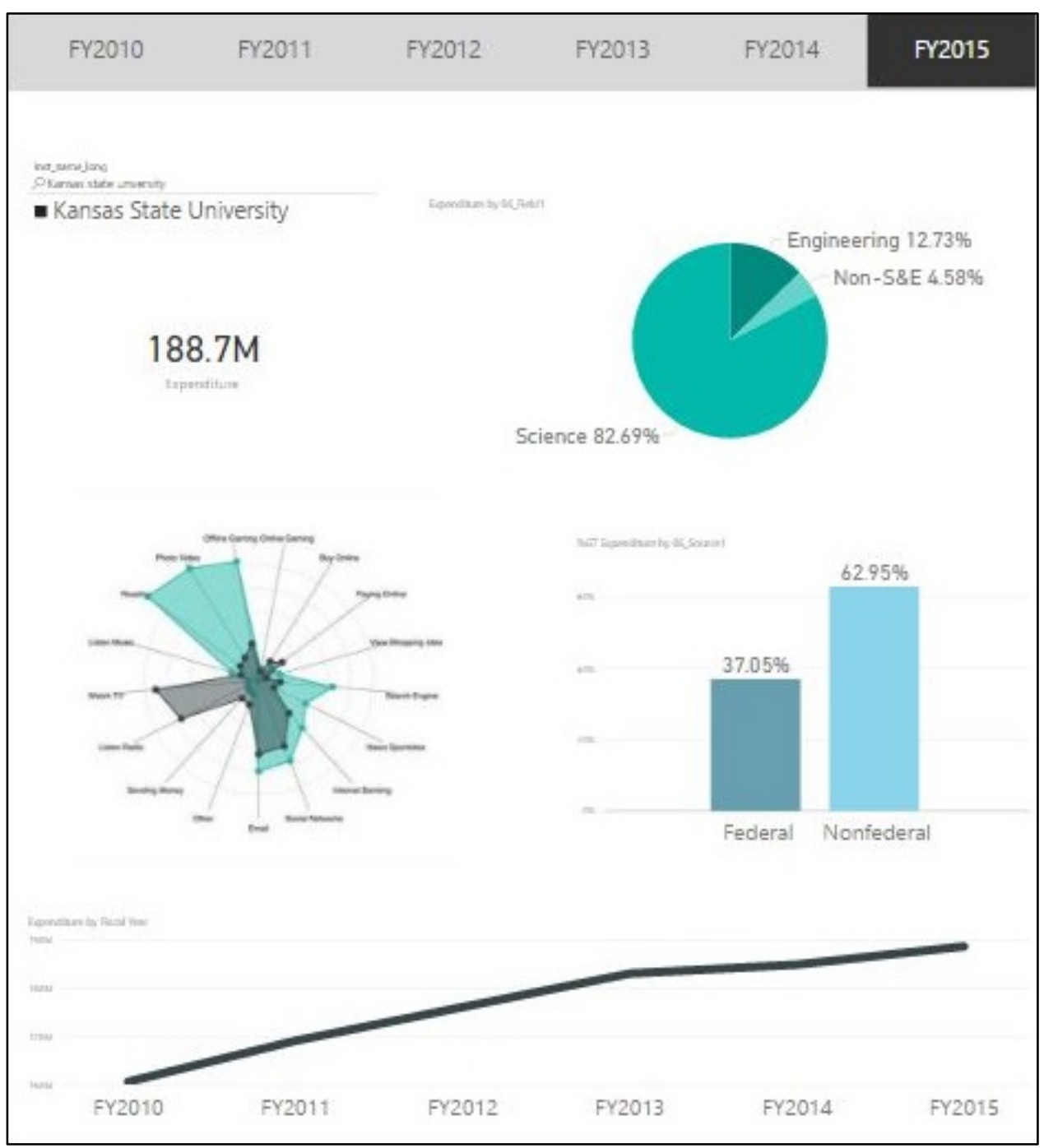

National Science Foundation 2010 - 2015 Higher Education Research and Development ${ }^{5}$

\section{Future efforts}

To date, our efforts have been focused on monitoring Kansas State University's performance towards our institutional goals, though our efforts could be leveraged to go beyond just monitoring. Under the leadership of the Vice President for Research, we are utilizing this wealth of information regarding our research activities to align researchers with applicable funding opportunities, highlighting interdisciplinary partners, and move Kansas State University's research efforts forward. Though Kansas State University has set a lofty goal, being recognized as one the nation's Top 50 Public Research Universities by $2025^{1}$, we have the research talent, leadership, and the insight into our data to meet the bold vision of K-State 2025. 


\section{References}

${ }^{1}$ http://www.k-state.edu/2025/

${ }^{2}$ https://wayback.archive-it.org/5902/20160210143434/http://www.nsf.gov/statistics/rdexpenditures/dst/

${ }^{3}$ https://wayback.archive-it.org/5902/20160210143410/http://www.nsf.gov/statistics/nsf99336/

${ }^{4}$ https://ncsesdata.nsf.gov/herd/2015/

${ }^{5}$ https://www.nsf.gov/statistics/srvyherd/ 